\title{
Corporate Social Responsibility (CSR): Opportunities and Challenges of Banking Sector in Bangladesh
}

\author{
Masud Rana \\ Department of Business Administration, Faculty of Business Studies, Pabna University of Science and Technology, Pabna, Bangladesh
}

\section{Email address:}

Masud7648@gmail.com

\section{To cite this article:}

Masud Rana. Corporate Social Responsibility (CSR): Opportunities and Challenges of Banking Sector in Bangladesh. Journal of Finance and Accounting. Vol. 3, No. 6, 2015, pp. 234-246. doi: 10.11648/j.jfa.20150306.20

\begin{abstract}
Corporate social responsibility (CSR) is now not a matter of the developed countries only but it is getting increased attention in developing countries like Bangladesh also. A strong perception has developed in recent years among the business managers in Bangladesh that they need to manage their organizations in a socially responsible way for economic viability and long term sustainability in the competitive marketplace. The paper aims to clearly understand the nature of CSR, investigates its evolution in Bangladesh, identifies the opportunities and challenges of CSR practices of banking sector in our country, and also makes some recommendations to overcome those challenges and make the CSR practice a success. Primary and Secondary data collection methods were used to conduct the study. From the study it is anticipated that there will be tremendous growth of CSR initiatives by many national and multinational companies in future.
\end{abstract}

Keywords: Corporate Social Responsibility, Social Performance, Challenges and Opportunities, Societal Marketing

\section{Introduction}

Social concerns are not a new area of interest for the business world. Corporate social responsibility (CSR) simply refers to strategies by which corporations or firms conduct their business in a way that is ethical and society friendly. CSR can involve a range of activities such as working in partnership with local communities, socially sensitive investment, developing relationships with employees, customers and their families, and involving in activities for environmental conservation and sustainability.

That means, for any business to sustain and grow in the long term, it cannot see itself as being isolated from the community around it. The community must mean people and the broader environment in which we live. Thus business should invest responsibly, avoiding projects where the potential for environmental damage outweighs the economic benefits, and ensure the welfare of different internal and external stakeholders.

In the 19th century, several industrialists in Europe and the US were noted for their concern for society, housing, welfare, charity to workers and their families. With the advent of the 20th century and the general adoption of legislation and social welfare systems, the spirit of charity and philanthropy then prevailing gave way to more formal relations and institutional structures. (European Foundation for the Improvement of Living and Working Conditions, 2003).

The concept of CSR is still very new in Bangladesh. In recent years there is considerable pressure from various agencies for companies to act responsibly and be accountable for the impacts they have on social, political and ecological environments.

CSR is important, therefore, because it influences all aspects of a company's operations- from sourcing to final servicing. Conscious consumers want to buy products from companies they know, believe, \& trust, suppliers want to form business partnerships with companies they can rely on, employees want to work for companies they respect $\&$ get honor, reputed large investors want to support firms that they perceive to be socially responsible, and welfare, nonprofits and NGOs want to work together with companies seeking practical solutions to common shared goals. The study tries to provide a broad view of CSR, its evolution particularly in Bangladesh, the opportunities originated from CSR practice and the challenges faced by financial organizations in Bangladesh while practicing and implementing CSR programs.

\subsection{Review of Literature}

Ahmed (2013) identified that demand for accountability and transparency from the both public and private sectors has 
become soaring. In the older days' management is seeking for survival and profits. Nowadays management concerns managing financial and nonfinancial results with awareness of risk and maintenance of transparency. As a result, Corporate Social Responsibility (CSR) has possessed equal importance of corporate financial performance. This paper explores how private commercial banks practices Corporate Social Responsibility (CSR) in Bangladesh in conserved the case of Southeast Bank Ltd. Banks' of Bangladesh practices CSR to not only improve community relations but also as source of significant commercial benefit. Southeast Bank Ltd. practices CSR under the rules and regulation of Bangladesh Bank. This study shows that Southeast Bank expenses BDT36.85 million in the year 2012 in the area of education, health, community development, environmental issue, art and culture, sports etc. Nevertheless, bank expenses highest amount in education sector through scholarship program in Bangladesh whereby school, college and university education tuition and expenses have fully paid for unconditionally.

Chowdhury (2013) at the MRDI's lessons learnt document launching ceremony said that Corporate Social Responsibility (CSR) is mainly about the awareness of and actions in support of environmentally sustainable societal development. CSR actions aim at mitigating the diverse environmental impacts of the activities of the business and at reducing inequalities and alleviating deprivation and poverty in the communities across the country. The banking sector is in a leading position in discharging CSR in the country and the CSR practices by the banks have become an integral part of their business in recent years. CSR practices by the banks not only improve their own standards but also catalyze the socially responsible behavior of other businesses. He also talks about the CSR benefits such as building reputation, increasing brand value, creating customer loyalty, employee motivation and retention, mitigating risks in own operation and in assessing supplier and clients, getting tax waiver on socially and environmentally responsible business lines etc.

Rahman (2013) defends that corporate social responsibility (CSR) has been gaining grounds during last few years in our country and today it is undoubtedly seen as an integral part of doing business globally. The definition of sustainable development as "developments that meets the needs of the present without compromising the ability of future generations to meet their own needs" also implies the continuation of the company as a going concern apart from serving society and natural capital. The banking sector has already emerged as the most important player in practicing CSR in the country. There were no precise policies on CSR policies in Bangladesh prior to 2008. In 2008, Bangladesh Bank (BB) took initiatives for formalizing CSR in the banking sector of Bangladesh and issued a detailed directive titled "Mainstreaming corporate social responsibility (CSR) in banks and financial institutions in Bangladesh"

Reed (2013) recommends that Bangladesh has many opportunities for economic growth and social development but also many hurdles to overcome in moving to the status of a developing or a developed country. The hurdles include economic, education \& health deficit. The international business community now generally understands that social responsibility has a much broader remit than the current Bangladesh practice of Corporate Socially Responsibility (CSR). Here CSR is still largely focused on donations and community investment, a practice now internationally regarded as corporate philanthropy and as only a part of CSR. The amount of money available for social development, funded through CSR donations, is increasing year by year.

Doshi \& Khokle (2012) suggest that internal organizational factors may enable or inhibit CSR, institutional players such as industrial associations, institutional investors, labour unions, consumers, media, and the government is equally important determinants of CSR activity of an organization. Organizations with strong labour unionization act in more socially responsible manner towards their employees. These organizations fear retaliation or bad reputation among their employees as well as the society at large. Due to the bandwagon effect, a growing number of adopters of an adaptive change drive a focal organization to subsequently adopt a similar change. Firms will participate more in CSR when other firms in the same industry have participated.

Masud \& Hossain (2012) argue that business organizations in the society are accountable to implement different socially desirable activities not only for stakeholders concern but also for different external parties. CSR reporting can be a significant part in the financial reporting while it provides information to different stakeholders and as an additional part social report would provide information relating to whole environmental concern to society. Previously Corporate Social Responsibility (CSR) reporting was a matter of developed countries. Now in the age of information CSR reporting plays a vital role in the developing countries like Bangladesh. The paper tries to find out CSR reporting practices of selected Banks in consideration of finance act 2010 and 2011. The study revealed that $100 \%$ Banks reported their CSR activities but it is also a matter of concern that less than $60 \%$ Banks participated in prescribe CSR areas according to finance act. The study reveals that there are 25 areas of CSR expenditure. Nevertheless, not a single bank participated in all of the specified areas. Maximum participation is not more than (55\%) of areas. Moreover, banks are clearly ahead in disclosing information in the annual report. All sampled banks (100\%) disclosed their CSR activities in the annual report. The study finds out that provided information generalized both financial and nonfinancial. $70 \%$ disclosed information is financial in nature.

Rana, Kalam \& Halimuzzaman (2012) suggest that business all over the world have practiced only profit making actions at past but not for long as the enterprise started to develop complexities and wideness in size and actions so was their reach getting bigger and bigger. A company's sense of responsibility towards the community and environment (both ecological and social) in which it operates called corporate 
social responsibility. Companies express this citizenship (1) through their waste and pollution reduction processes, (2) by contributing educational and social programs, and (3) by earning adequate returns on the employed resources. This article finds out the CSR practices of DBBL and its shortcomings and also recommends some courses of action. The areas in which DBBL practices CSR activities are education, health, disaster, donation, sports Sector and Other Sectors.

Mohin (2012) finds out the top ten trends in CSR for 2012 such as going global- the relentless march toward globalization will continue to stretch the scope of corporate responsibility, the triumph (or tyranny) of transparency- the pressure for ever increasing levels of transparency and disclosure will build, employee engagement emerges- the connection between CSR and engaged employees continues to grow, political pitfalls-CSR leaders should choose what they promote wisely and set clear boundaries to avoid becoming political footballs, collaboratition-companies will both compete and collaborate on CSR issues, human rightscompanies have been waking up to human rights issues across their value chains, earth at seven billion and growingas more than seven billion people compete for the Earth's resources, the need to be more efficient will continue to increase etc.

CSR Centre (2012) recommends that the growth of responsible business practices in Europe and North America is driving change within both the private and public sectors in developing countries like Bangladesh. The private sector in Bangladesh is beginning to recognize that corporate social responsibility (CSR) goes beyond philanthropy and compliance offers companies an opportunity to build new supply chain relationships, access new local and overseas markets, and ultimately, ensure long-term profits and sustainability. At the same time, these opportunities enable the private sectors to achieve millennium development goals (MDGs). This report thus defines CSR, incorporates the emergence of CSR in Bangladesh, provides some motivations of CSR practice such as community development, makes good business sense, responsibility to employee and community welfare, developing communities in ways that benefits business, create shared value, operate responsibly etc.

Vaidyanathan \& Scott (2012) suggest that creating shared value means closely examining the linkages between economic and social progress. When businesses invest to spur better health, improve education, and generate higher productivity, they expand their customer base and increase the purchasing power for their goods and services. Creating shared value is actually going beyond traditional CSR approaches. Shared value differs from traditional CSR in that it compels firms to view social progress as a key factor in the development of their business strategy. It requires companies to break previous assumptions that tradeoffs exist between social good and corporate profitability. This paper identifies some advantages of CSR practice such as increasing corporate reputation, license to operate, social benefits of successful projects, risk reduction and goodwill etc.

Robbins (2011) suggests that most executives believe that CSR can improve profits. They understand that CSR can promote respect for their company in the marketplace which can result in higher sales, enhance employee loyalty and attract better personnel to the firm. Also, CSR activities focusing on sustainability issues may lower costs and improve efficiencies as well. This paper also indicates that surveys and the research literature suggest that what most executives believe intuitively, that CSR can improve profits, is possible. And almost no large public company today would want to be seen unengaged in CSR. That is clear admission of how important CSR might be to their bottom line, no matter how difficult it may be to define CSR and link it to profits.

Scarlett (2011) argues that Companies are incentivized to engage in socially responsible programs because of the potential benefits to business, which includes brand enhancement, market differentiation, and employee satisfaction. However, companies often fail to effectively communicate their CSR activities to target audiences, which can hinder the company's realization of these business benefits. This paper identifies some opportunities that can be originated from CSR such as Improve stakeholders perceptions of the company, improve company or brand image (as stated by Barone et al., 2007, p. 444), establish a positive corporate reputation that makes consumers resilient to negative company news (as stated by Du et al., 2007), enhanced consumers' evaluations of the company (as stated by Sen \& Bhattacharya, 2001), positive word of mouth communication etc.

D'Amato, Henderson, \& Florence (2009) in the book Corporate Social Responsibility and Sustainable Business: A Guide to Leadership Tasks and Functions argue that corporations around the world are struggling with a new role, which is to meet the needs of the present generation without compromising the ability of the next generations to meet their own needs. Organizations are being called upon to take responsibility for the ways their operations impact societies and the natural environment. A firm must now focus its attention on both increasing its bottom line and being a good corporate citizen. For these, organizations have developed a variety of strategies for dealing with this intersection of societal needs, the natural environment, and corresponding business imperatives. This book also give some Organizational Challenges and Limitations in practicing CSR as stated by Lewicka-Stralecka (2006) who identifies the opportunities and limitations of CSR in the so-called countries of transformation, or Central and Eastern European countries such as- the business image, the legal background, the job-market situation, the corruption and the correlates of economic stagnation and social decline, the socialist associations.

Belal (2001) suggests that Corporate social responsibility (CSR) is the process of communicating the social and environmental effects of organization's economic actions to particular interest groups within society and to society at large. As such, it involves extending the accountability of 
organizations (particularly companies), beyond the traditional role of providing a financial account to the owners of capital, in particular, shareholders. The purpose of this paper is to put CSR practices in Bangladesh into context. As noted earlier, corporate reporting in general and CSR in particular is greatly influenced by social, political, cultural, legal, economic and technological factors, so this paper measures the extent and volume of disclosures of CSR practices in Bangladesh by using content analysis, and explores the socio-political and economic context in which these disclosures take place. CSR practices in Bangladesh have been examined in this article under three disclosure categories as employee disclosures, ethical disclosures, and other disclosures.

Institute for Crisis Study and Alternative Development Strategy, Indonesia (2011) recommends that the worker and the trade union, both stakeholders in the company, are certainly affected by a company's CSR policy and its implementation. This paper focus on the implementation of CSR and its effects on workers and trade unions with the assumptions that the content of a CSR program is everything that the company contributes towards the worker's welfare other than that which is already included in the labor laws and working agreement or in the collective labor agreement, reinforcing the believe that the leitmotiv of CSR program is to divert worker's demand or to weaken, and gradually eliminate the trade union.

Bronchain (2003) in his book Towards a sustainable corporate social responsibility clarifies the concept of CSR, give a clear understanding of the subject by identifying the actors, approaches and conditions necessary for its growth, identify its added value in terms of economic and social progress and put forward recommendations for future actions. The studies in this respect identified the following main motives for acting in a socially responsible way: Developing new products and markets, Image, Appearing as an attractive workplace, \& Smooth running of the company. This book also find some challenges in practicing CSR such as improved skills required from know-how to attitudinal behavior, appropriate institutional supports etc.

\subsection{Objectives of the Study}

The main objectives of this study are as follows:

- To understand the meaning and nature of Corporate Social Responsibility (CSR).

- To acquire subjective perceptions about various CSR tasks of private commercial banks in Bangladesh.

- To find out the major areas where CSR activities are performing by private commercial banks in Bangladesh.

- To compare and analyze the contribution of CSR activities of private commercial banks in Bangladesh in different areas.

\subsection{Methodology of the Study}

Methodology is a system of broad principle or rule from which specific methods or procedures may be derived to interpret or solve different problems within the scope of a particular discipline. Methodology is not a formula but set of practices. The study was conducted to identify the problems and prospects of CSR in Bangladesh. Necessary data were collected from different prospect people in financial institution base on selected banking corporation and analyzed in terms of the objectives set for the study. The data for this study were collected by the survey method. Survey is are search technique in which information is gathered from a sample of prospect people by using of a questionnaire or interview.

\subsubsection{Sources of Data Collection}

\section{i. Primary Data:}

A structured (open end) questionnaire is designed to investigate the level of users understanding and their perception towards CSR. The sample of the study covers the banking employees from selected private ten commercial banks in Bangladesh. Sample size of 50 respondents' opinion has collected from top selected private commercial banks clients and employee's opinion for each respectively.

ii. Secondary Data:

Various Banks websites, periodicals, Bangladesh Bank's publications, newspapers are used as the secondary sources of the study. A list of related articles from various journals is also used to develop the basic idea about the particular topic and several international efforts and initiatives for developing and implementing CSR standards and guidelines will be examined.

iii. Questionnaire Data:

The questionnaire is starting with open-ended questions. These questions provide the basic information about respondents. These types of questions make respondents comfortable to respond the study. There are some core questions in this questionnaire. The respondents were asked the questions to know their knowledge and perception about CSR in banking corporation in Bangladesh.

\subsubsection{Data Analysis}

Hypothesis Testing:

Data are analyzed through hypothesis testing including $\mathrm{Z}$ test. After reviewing the literature the researchers have identified the following hypotheses.

Hypothesis 01: H0-CSR is not a tool to gain competitive advantages.

H1-CSR is a tool to gain competitive advantages.

Hypothesis 02: H0-CSR may not influence the employee's behavior positively.

H1-CSR may influence the employee's behavior positively

Hypothesis 03: H0-CSR has not a significant role in establishing a corporate image.

H1-CSR has a significant role in establishing a corporate image.

Hypothesis 04: H0-CSR may not influence the customer's behavior positively.

H1-CSR may influence the customer's behavior positively.

Hypothesis 05: H0-CSR may not influence the financial performance.

H1-CSR may influence the financial performance.

Hypothesis 06: H0-CSR may be not practice enough under regulation of the central bank. 
H1-CSR may be practice enough under regulation of the central bank.

The Hypotheses of the study have formulated in terms of Null hypothesis and Alternative hypothesis. The data have got from the questionnaire which had responses supporting either H0 (null hypotheses) or H1 (alternative hypotheses). The researchers have also decided to use Z-test, because, the sample size is more than 30 .

The calculating formula is: $Z=\frac{\mathrm{P}-p}{\sigma_{\mathrm{p}}}$.

Where, the level of significance for the test is $5 \%$.This makes the tabulated $\mathrm{Z}$ to be \pm 1.96 .

Here,

$n$-no of observation is 100 .

$P$ - population sample mean that is, $\mathrm{P}=\frac{\mathrm{x}}{\mathrm{n}}$.

$x$ - (support for the null hypothesis ) by the respondent's opinion given on each table.

$p$-population proportion where it is $20 \%$.

(it is assumed that population proportion is $20 \%$ although population proportion is not certain rather sample population is certain, this $20 \%$ is denoted Null hypothesis where I want to justify on the basics of Sample Proportion to population proportion that those Null hypothesis either reject or accept) $\sigma_{P}$ - Standard Deviation that is, $\sqrt{ } p(1-p) \div n$.

\section{Evolution of CSR in Bangladesh}

\subsection{Introduction}

Corporate social responsibility (CSR) is a vital concept for sustainable business in today's competitive and greener marketplace. Although CSR as a concept has gained immense popularity, there is a lack of agreement on what it really means. There are different expectations from different stakeholder groups, different standards, and different practices leading to a fragmented understanding of CSR.

There is one and only one social responsibility of businessto use it resources and engage in activities designed to increase its profits so long as it stays within the rules of the game, which is to say, engages in open and free competition without deception or fraud"by Milton Friedman in 2012 Good reads Inc.

Corporate Social Responsibility (CSR) has been gaining grounds during last few years in our country and today it is undoubtedly seen as an integral part of doing business globally. CSR is not only about doing philanthropy/charity or protecting the environment; it also aims at eradicating poverty and reducing deprivation among the poor/underprivileged segment of the society. Enhancing CSR as a means for poverty reduction and achieving sustainable development requires combined initiatives.

It would be motivating to derive a meaning of the concept with the dissection of each of the words. CSR is not a difficult concept and can be explained as:

- Corporate - means organized business.

- Social - means everything dealing with people, the society at large.
- Responsibility - means accountability between the two

Accordingly, CSR needs to be:

- more inwards than outwards,

- more related to the character and culture of the corporate rather than its size or profitability,

- more related to making and distributing profits and sustainability,

- more business process oriented than philanthropic,

- Corporate Philanthropy.

- Corporate Support.

- Sponsorships.

- Corporate Partnerships.

So, CSR can be defined as a concept whereby a business concern earn profit by obeying the existing law through doing the right things with moral duty and obligation to be a good corporate citizen. So, from the above analyses it can be declared that Corporate Social Responsibility (CSR) is a dynamic concept which is more reflecting the activities of the moral responsibility of companies for ecological and social consequences for ensuring sustainable development.

\subsection{CSR in Bangladesh}

CSR concepts and practices in Bangladesh have a long history of philanthropic activities from time immemorial. These philanthropic activities included donations to different charitable organizations, poor people and religious institutions. Till now, most of the businesses in Bangladesh are family owned and first generation businesses. They are involved in community development work in the form of charity without having any definite policy regarding the expenses or any concrete motive regarding financial gains in many instances. Moreover, most of the SMEs fall under the informal sector having low management structure and resources to address the social and environmental issues. These limitations drive the top management of local companies to think only about the profit maximization rather than doing business considering the triple bottom line: profit, planet and people.

The banking sector has already emerged as the most important player in practicing CSR in the country. CSR practices by them not only improve their own standards but also revolutionize the socially responsible actions of other businesses. Banking industry itself can also gain from the positive effects of CSR on the society as a whole, particularly on its clients.

\section{Descriptive Analysis and Empirical Findings of CSR}

\subsection{Descriptive Analysis}

\subsubsection{Highlights of CSR Activities of Bangladesh Financial Sector}

In August, 2013 Bangladesh Bank produces a comprehensive report for the first time in the history of Bangladesh Financial Sector by covering CSR practices of 
Bangladesh Financial Sector. Since 2010 CSR report has been published on the basis of the CSR activities of banks. Now, CSR practices of Non Bank Financial Institutions (NBFIs) in Bangladesh in a structured manner have been incorporated for the first time in this report. 29 NBFIs except Agrani SME Financing Company Limited (which has just started its operation) reported on their CSR activities in 2012. In 2012, they reported direct CSR expenditure of 16.75 million taka.

\subsubsection{Highlights of CSR Activities in Banks}

This section highlights the CSR activities of both the public and private banks excluding the new banks started their operation from late 2013.

- Total annual direct CSR expenditure of banks increased by Tk. 858.36 million then the previous year.

Table 1. Highlights of CSR Activities of Banks from 2009-2013.

\begin{tabular}{llllll}
\hline \multicolumn{6}{l}{ CSR expenditure by banks } \\
\hline Year & $\mathbf{2 0 0 9}$ & $\mathbf{2 0 1 0}$ & $\mathbf{2 0 1 1}$ & $\mathbf{2 0 1 2}$ & $\mathbf{2 0 1 3}$ \\
\hline $\begin{array}{l}\text { BDT } \\
\text { (Million) }\end{array}$ & 410.7 & 553.80 & 2329.80 & 2188.33 & 3046.69 \\
\hline
\end{tabular}

- As in preceding years, CSR initiatives of banks in 2013 continued focus on i) financial inclusion of less privileged population segments and underserved economic sectors, ii) emergency relief in humanitarian distresses, iii) promotion of health, education and cultural/recreational activities for advancement and wellbeing of underprivileged population segments, iv) promotion of environment friendly projects. Besides continuation and expansion of previous engagements in these areas, interesting newer directions/newer thrusts seen in the 2013 CSR reports of banks included:

- A safe drinking water project was commenced by one of the banks to provide safe water to 0.25 million people and sanitation to 0.4 million people in the northeast and north-western regions of Bangladesh.

- Distribution of sewing machines among the women of
Somvupura union under Sonargaonupazila for increasing their self-reliance and well off condition.

- Distribution of formalin D-Hydrate Machine to Malibag Bazar Banik Samabay Samity Ltd. for detecting formalin mixed product.

- Establishing a woman's training center at Bashatpur, Jessore to train and rehabilitate poor and helpless women especially those who are victims of human trafficking.

- Establishing 'Gaon Shwapno'-an initiative supporting marketing of crafts and services produced by distressed poor women.

- Introducing Krishak Card for farmers of northern region of the country to enable them to buy seeds, fertilizer, pesticides and other agricultural materials.

- Undertaking projects promoting low carbon emission where recycled papers are used as raw materials for production of finished goods, leading to conservation of trees.

\subsubsection{Trends of Sectorial Pattern of Direct CSR} Expenditure Reported by the Banking Sector

The respondents' were asked to give their opinion regarding the level of importance of some important sectors of CSR practices. For descriptive analysis, the researchers considered the mean and standard deviation of the sectors of CSR practices. On the basis of respondents significant opinion following table and graph are designed.

Table 2. Sectorial patterns of CSR in banks.

\begin{tabular}{llll}
\hline No. & Sectorial Patterns of CSR & Mean & SD \\
\hline 1 & Education & 3.80 & 1.89 \\
2 & Health Care & 3.67 & 1.80 \\
3 & Sports & 3.48 & 1.17 \\
4 & Others & 3.33 & 1.15 \\
5 & Humilities and disaster Relief & 3.12 & 1.10 \\
6 & Arts and Culture & 2.95 & 0.96 \\
7 & Environment & 2.76 & 0.89 \\
\hline
\end{tabular}

(Source: "Review of CSR initiative of banks"; Bangladesh Bank 2013).

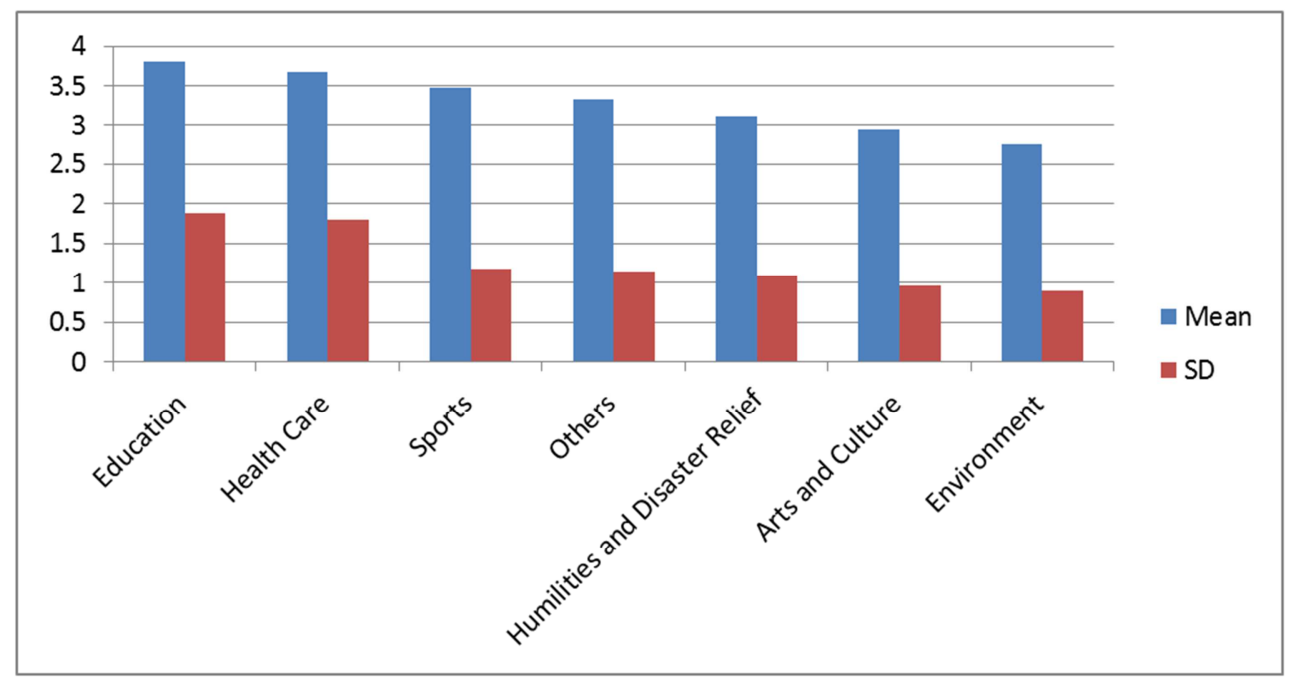

Figure 1. Sectorial patterns of CSR in banks. 
From the above table and graph indicate that the private commercial banks have given the more concentrations in the sector of education followed by healthcare, sports, humilities \& disaster relief and others. The CSR initiatives has proved that the respondents opinion is accurate because in 2013 the Sectorial pattern of CSR expenditure BDT (million) private commercial banks in Bangladesh is given below with a chart and figure.

The following section provides an overview of sectoral pattern of direct CSR expenditure reported by the various banking financial institutions in Bangladesh.

Table 3. Trends of sectoral pattern of CSR expenditure reported in bank (Tk. in million).

\begin{tabular}{|c|c|c|c|c|c|c|c|c|c|c|c|c|}
\hline \multirow{2}{*}{ Sectors } & \multicolumn{2}{|l|}{2008} & \multicolumn{2}{|l|}{2009} & \multicolumn{2}{|l|}{2010} & \multicolumn{2}{|l|}{2011} & \multicolumn{2}{|l|}{2012} & \multicolumn{2}{|l|}{2013} \\
\hline & Amount & $\%$ & Amount & $\%$ & Amount & $\%$ & Amount & $\%$ & Amount & $\%$ & Amount & $\%$ \\
\hline $\begin{array}{l}\text { Humanitarian\& } \\
\text { disaster relief }\end{array}$ & 127.70 & 56.40 & 58.60 & 14.27 & 125.10 & 22.59 & 460.41 & 19.76 & 188.03 & 8.59 & 788.37 & 25.88 \\
\hline Education & 14.30 & 6.32 & 30.50 & 7.43 & 94.80 & 17.12 & 400.79 & 17.20 & 612.48 & 27.99 & 983.69 & 32.29 \\
\hline Health & 68.60 & 30.30 & 112.10 & 27.29 & 245.50 & 44.33 & 689.07 & 29.58 & 520.42 & 23.78 & 435.43 & 14.29 \\
\hline Sports & 2.70 & 1.19 & 49.80 & 12.13 & 1.20 & 0.22 & 265.23 & 11.38 & 359.07 & 16.41 & 183.85 & 6.03 \\
\hline Art \& culture & 0.00 & 0.00 & 0.80 & 0.19 & 0.30 & 0.05 & 328.91 & 14.12 & 171.52 & 7.84 & 213.31 & 7.00 \\
\hline Others & 13.10 & 5.79 & 158.90 & 38.69 & 86.90 & 15.69 & 125.58 & 5.39 & 198.73 & 9.08 & 301.81 & 9.91 \\
\hline Total & 226.40 & 100 & 410.70 & 100 & 553.80 & 100 & 2329.8 & 100 & 2188.33 & 100 & 3046.69 & 100 \\
\hline
\end{tabular}

(Source: "Review of CSR initiative of banks"; Bangladesh Bank 2013).

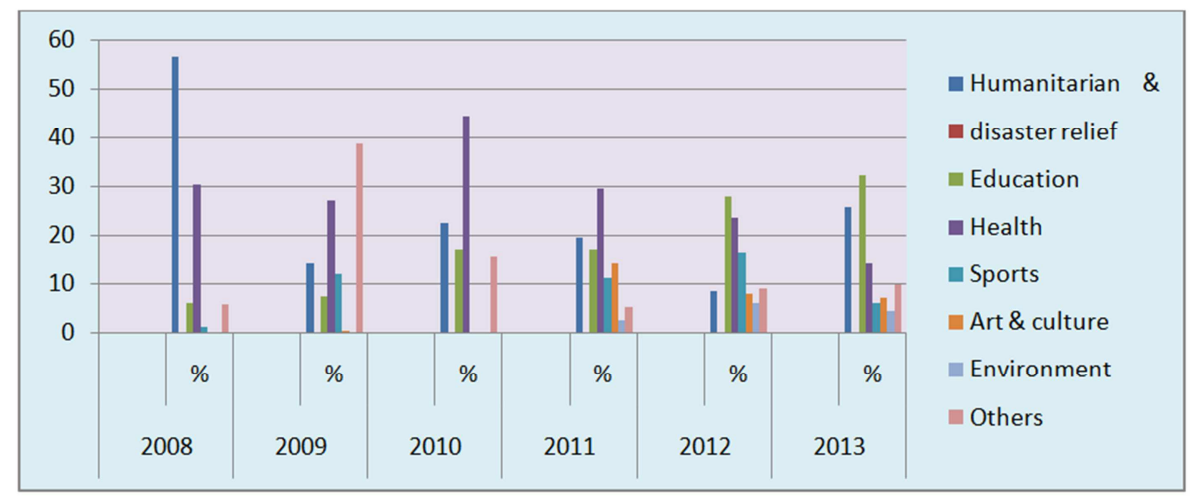

Figure 2. Trends of sectoral pattern of CSR expenditure reported in banks (Percentage).

Though, CSR expenditure in health sector reduced from the previous year but the banks continued to maintain major share in education, health and humanitarian \& disaster relief. Education, health, humanitarian and disaster relief contributed to $32.29 \%, 14.29 \%$ and $25.88 \%$ share respectively. i.e. $72.46 \%$ out of total CSR expenditure. Expenditure on sports (7\%), Art and culture (7.84\%) and environment (4.60\%) decreased in 2013.

Notable specific share of expenditure in CSR programs of banks in 2013 are as follows by chart:

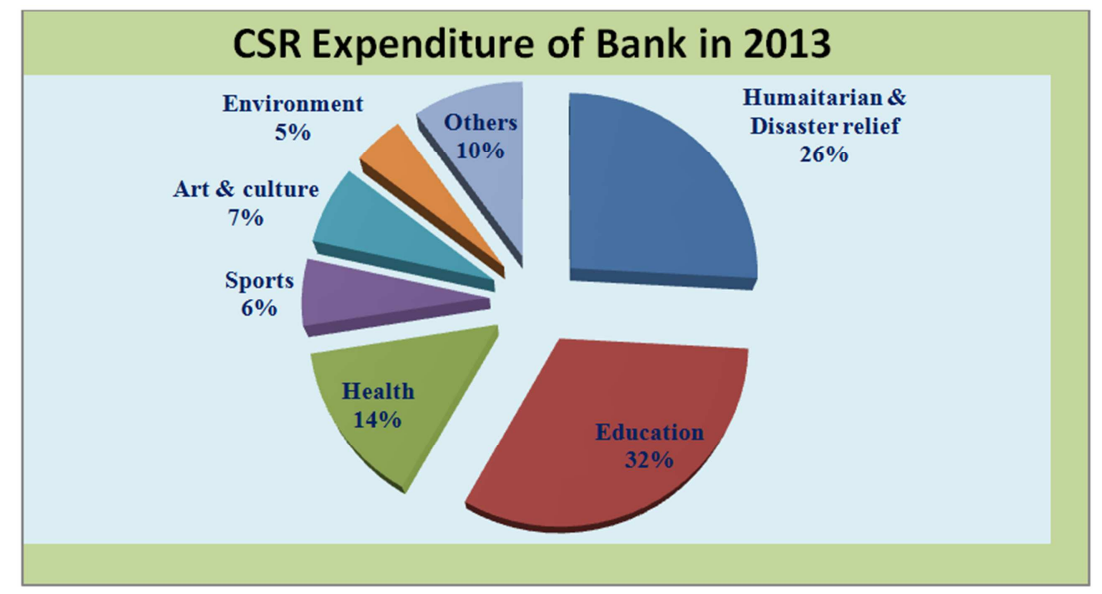

(Source: "Review of CSR initiative of banks"; Bangladesh Bank 2013).

Figure 3. Expenditure in CSR programs of banks in 2013 
- Education sector (32.29\%) got the highest weight as percentage of total CSR expenditure in 2013 like 2012. About $16.98 \%$ and $20.79 \%$ of the expenditure is for scholarship to poor and meritorious female and male students respectively. Of this $4.45 \%$ is lump grant to physically challenged students and other $57.70 \%$ is for purchasing books and clothing etc.

- CSR expenditures of banks in the health sector continued to contribute in established hospitals, clinics etc. as well as arranging free health treatment camp, blood donation program etc. in 2013.

- Banks are paying due attention to gender fairness issues in their internal work environment, recruitment, maternity leave policies etc. and are reporting to BB on gender issues like the previous year.

- CSR expenditures of banks as percentage of their after tax profit range from $0.16 \%$ to $71.23 \%$. The percentages are in double digits for 6 PCBs which were for 3 PCBs in 2012.

So, in the year 2013, the 'Education' and 'Humanitarian \& disaster relief' sectors were getting more attention and appeared to be the most popular sectors for CSR activities as huge investments are being made by several banks in these segments. As earlier the researchers mentioned, the banks are expending in CSR purpose is increasing gradually.

\subsubsection{A Comparative Analysis of CSR Practices by the Ten Selected Private Commercial Banks}

The banking sector of Bangladesh has a long history of involvement in benevolent activities like donations to different charitable organizations, to poor people and religious institutions, city beautification and patronizing art $\&$ culture, etc. Recent trends of these engagements indicate that banks are gradually organizing these involvements in more structured CSR initiative. The researchers have selected ten special areas of CSR practices and made a comparison between the banks on the basis of respondents' significant opinion. For such comparison, the researchers assumed the selected areas of CSR to be $100 \%$ and it is shown following (table-4):

Table 4. Direct CSR expenditures reported by banks from 2008-2013 (Amount in Taka).

\begin{tabular}{llllllll}
\hline & Name of Bank & $\mathbf{2 0 0 8}$ & $\mathbf{2 0 0 9}$ & $\mathbf{2 0 1 0}$ & $\mathbf{2 0 1 1}$ & $\mathbf{2 0 1 2}$ & $\mathbf{2 0 1 3}$ \\
\hline 1 & IBB & - & - & $116,270,000$ & $232,631,000$ & $410,700,000$ & $309,100,000$ \\
2 & EBL & $9,500,000$ & $1,000,000$ & $6,738,669$ & $31,317,000$ & $11,900,000$ & $21,037,610$ \\
3 & SIBL & - & - & - & $24,689,080$ & $24,484,990$ & $52,918,600$ \\
4 & DBBL & $39,206,500$ & $171,016,500$ & $159,206,500$ & $168,860,000$ & $341,830,000$ & $527,670,000$ \\
5 & NCC & - & $11,000,000$ & $4,380,000$ & $17,700,000$ & $8,500,000$ & $17,400,000$ \\
6 & CITY & - & - & $4,980,000$ & $11,703,000$ & $1,351,500$ & $5,676,734$ \\
7 & FISBL & $400,000.00$ & $1,000,000$ & - & $43,630,000$ & $80,850,500$ & $90,409,070$ \\
8 & SBEL & $22,414,000$ & $14,654,375$ & - & $38,400,000$ & $15,100,000$ & $14,100,000$ \\
9 & TRUST & $9,520,000$ & $1,000,000$ & $46,750,000$ & $48,100,000$ & $81,200,000$ & $130,200,000$ \\
10 & EXIM & - & $19,300,000$ & - & $231,825,000$ & $180,900,000$ & $399,000,000$ \\
\hline
\end{tabular}

Table 4. Continued.

\begin{tabular}{lllll}
\hline & $\begin{array}{l}\text { CSR Expenses as \% of Profit } \\
\text { After tax in 2012 }\end{array}$ & $\begin{array}{l}\text { CSR Expenses as \% of } \\
\text { Profit After tax in 2013 }\end{array}$ & $\begin{array}{l}\text { CSR Expenditure in Education as \% of } \\
\text { Total CSR Expenditure in 2012 }\end{array}$ & $\begin{array}{l}\text { CSR Expenditure in Education as \% } \\
\text { of Total CSR Expenditure in 2013 }\end{array}$ \\
\hline 1 & $6.49 \%$ & $5.63 \%$ & $13.71 \%$ & $27.08 \%$ \\
2 & $0.47 \%$ & $0.91 \%$ & $47.06 \%$ & $48.73 \%$ \\
3 & $1.94 \%$ & $3.48 \%$ & $2.57 \%$ & $18.44 \%$ \\
4 & $15.87 \%$ & $22.86 \%$ & $62.40 \%$ & $62.94 \%$ \\
5 & $0.39 \%$ & $1.25 \%$ & $41.18 \%$ & $29.89 \%$ \\
6 & $0.06 \%$ & $0.74 \%$ & $24.05 \%$ & $13.28 \%$ \\
7 & $13.29 \%$ & $10.61 \%$ & $15.70 \%$ & $25.58 \%$ \\
8 & $0.50 \%$ & $0.93 \%$ & $53.64 \%$ & $7.09 \%$ \\
9 & $13.18 \%$ & $71.23 \%$ & $54.93 \%$ & $54.22 \%$ \\
10 & $8.71 \%$ & $18.70 \%$ & $9.20 \%$ & $11.45 \%$ \\
\hline
\end{tabular}

From the above table, it is clear that DBBL (Dutch Bangla Bank Ltd), covers the more areas than the other private commercial banks and its percentage is $90 \%$ out of $100 \%$. It also indicates, DBBL practices CSR in diversified areas of the society. The EBL, FSIBL, Trust bank and EXIM bank have also a good contribution to CSR and deal with different areas of CSR. The rest of the private commercial banks have also contribution to CSR which is less than $50 \%$. This makes a clear picture that the banks are not concerned with all the areas of CSR including technical and vocational training to labor for export of HR, accommodation for slum dwellers and feeding \& clothing \& rehabilitation of rootless children.

The review of CSR initiative of banks (2013) has mentioned the top five private commercial banks of Bangladesh on the basis of the contribution of CSR which is shown in the following chart. 


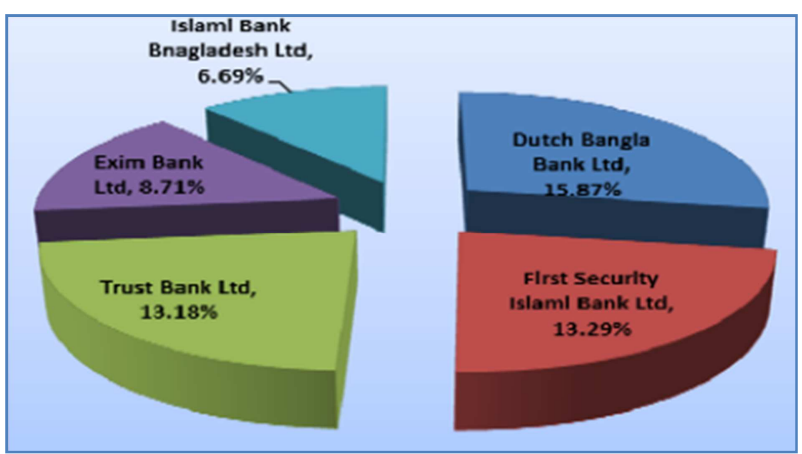

(Source: "Review of CSR initiative of banks"; Bangladesh Bank 2013).

Figure 4. Top Five Private Commercial Banks.

This figure also proves that the respondents' opinion is accurate because if the table analyzed the top five banks DBBL (90\%), FSIBL (70\%), Trust bank Ltd (60\%), EXIM $(50 \%)$ and IBBL $(40 \%)$ are same which has mentioned by CSR initiative of Bangladesh Bank, 2013.

\subsection{Empirical Analysis and Findings of the Study}

\subsubsection{Hypotheses Testing}

Hypothesis-One:

CSR is a tool to gain competitive advantages.

$\mathrm{H} 0=\mathrm{CSR}$ is not a tool to gain competitive advantages.

$\mathrm{H} 1=\mathrm{CSR}$ is a tool to gain competitive advantages.

Table 5. Opinion of The respondents on Competitive advantage.

\begin{tabular}{lll}
\hline Nature of Responses & No. Of Responses & Percentages (\%) \\
\hline YES & 88 & $88 \%$ \\
NO & 12 & $12 \%$ \\
Total collected data & 100 & $100 \%$ \\
\hline
\end{tabular}

Sources: Field survey.

From the table out of 100 respondents, 88 yes that CSR is a tool to gain competitive advantages and only 12 respondents supported null hypothesis (H0).

So $\mathrm{H} 0=\mathrm{CSR}$ is not a tool to gain competitive advantages and alternative hypothesis

$(\mathrm{H} 1)=\mathrm{CSR}$ is a tool to gain competitive advantages.

The calculated value of $\mathrm{Z}$ is $1-2.00$ land table value is 11.96।. (By using the formula of- $Z$ ).

Here, calculated value of $\mathrm{Z}$ is greater than table value.

So, it can reject the null hypotheses and accept the alternative hypothesis, CSR is tool to gain competitive advantages.

Hypothesis -Two:

CSR may influence the employee's behavior positively.

$\mathrm{H} 0=\mathrm{CSR}$ may not influence the employees' behavior positively.

H1=CSR may influence the employees' behavior positively.

Table 6. Opinion of The respondents on employee's behavior.

\begin{tabular}{lll}
\hline Nature of Responses & No. Of Responses & Percentages \\
\hline YES & 90 & $90 \%$ \\
NO & 10 & $10 \%$ \\
Total collected data & 100 & $100 \%$ \\
\hline
\end{tabular}

Sources: Field survey.
From the table out of 100 respondents, 90yes that CSR may influence the employees' behavior positively and only 10 respondents supported null hypothesis $(\mathrm{H} 0)$.

So $\mathrm{H} 0=\mathrm{CSR}$ may not influence the employees' behavior positively.

$(\mathrm{H} 1)=\mathrm{CSR}$ may influence the employees' behavior positively.

The calculated value of $Z$ is $1-2.50$ and table value is 11.96|. (By using the formula of- $Z$ ).

Here, calculated value of $\mathrm{Z}$ is greater than table value.

So, it can reject the null hypotheses and accept the alternative hypothesis, CSR is tool to gain competitive advantages.

Hypothesis-Three:

CSR has a significant role in establishing a Bank's image.

$\mathrm{H} 0=\mathrm{CSR}$ has no significant role in establishing a bank's image.

$\mathrm{H} 1=\mathrm{CSR}$ has a significant role in establishing a bank's image.

Table 7. Opinion of The respondents on Creating Bank's image.

\begin{tabular}{lll}
\hline Nature of Responses & No. Of Responses & Percentages (\%) \\
\hline YES & 91 & $91 \%$ \\
NO & 09 & $9 \%$ \\
Total collected data & 100 & $100 \%$ \\
\hline
\end{tabular}

Sources: Field survey.

From the table out of 100 respondents, 91yes that CSR has a significant role in establishing a bank's image and only 09 respondents supported null hypothesis $(\mathrm{H} 0)$.

So $\mathrm{H} 0=\mathrm{CSR}$ has no significant role in establishing a bank's image.

$(\mathrm{H} 1)=$ CSR has a significant role in establishing a bank's image.

The calculated value of $\mathrm{Z}$ is $\mid-2.75$ land table value is 11.96।. (By using the formula of- $Z$ ).

Here, calculated value of $Z$ is greater than table value.

So, it can reject the null hypotheses and accept the alternative hypothesis, CSR has a significant role in establishing a bank's image.

Hypothesis-Four:

CSR may influence the customer's behavior positively.

$\mathrm{H} 0=\mathrm{CSR}$ may not influence the customer's' behavior positively.

H1=CSR may influence the customer's' behavior positively.

Table 8. Opinion of The respondents on Customer's.

\begin{tabular}{lll}
\hline Nature of Responses & No. Of Responses & Percentages \\
\hline YES & 85 & $85 \%$ \\
NO & 15 & $15 \%$ \\
Total collected data & 100 & $100 \%$ \\
\hline
\end{tabular}

Sources: Field survey.

From the table out of 100 respondents, 85yes that CSR may influence the customer's' behavior positively and only 15 respondents supported null hypothesis (H0). 
So H0=CSR may not influence the customer's' behavior positively.

H1=CSR may influence the customer's' behavior positively.

The calculated value of $\mathrm{Z}$ is $1-1.25$ land table value is 11.96।. (By using the formula of- $Z$ ).

Here, calculated value of $\mathrm{Z}$ is lower than table value.

So, it can accept the null hypotheses and reject the alternative hypothesis, CSR may not influence the customer's' behavior positively.

Hypothesis-Five:

Whether CSR may influence the financial performance.

$\mathrm{H} 0=\mathrm{CSR}$ may not influence the financial performance.

$\mathrm{H} 1=\mathrm{CSR}$ may influence the financial performance.

Table 9. Opinion of The respondents on financial performance of Bank.

\begin{tabular}{lll}
\hline Nature of Responses & No. Of Responses & Percentages \\
\hline YES & 90 & $90 \%$ \\
NO & 10 & $10 \%$ \\
Total collected data & 100 & $100 \%$ \\
\hline
\end{tabular}

Sources: Field survey.

From the table out of 100 respondents, 90yes that CSR may influence the financial performance and only 10 respondents supported null hypothesis (H0).

So $\mathrm{H} 0=\mathrm{CSR}$ may not influence the financial performance.

$(\mathrm{H} 1)=$ CSR may influence the financial performance.

The calculated value of $\mathrm{Z}$ is $1-2.50$ and table value is 11.96|. (By using the formula of- $Z$ ).

Here, calculated value of $\mathrm{Z}$ is greater than table value.

So, it can reject the null hypotheses and accept the alternative hypothesis, CSR may influence the financial performance.

Hypothesis-Six:

Whether CSR may be practice enough under regulation of the central bank.

$\mathrm{H} 0=\mathrm{CSR}$ may not be practice enough under regulation of the central bank.

$\mathrm{H} 1=\mathrm{CSR}$ may be practice enough under regulation of the central bank.

Table 10. Opinion of The respondents on central bank's regulation.

\begin{tabular}{lll}
\hline Nature of Responses & No. Of Responses & Percentages \\
\hline YES & 83 & $83 \%$ \\
NO & 17 & $17 \%$ \\
Total collected data & 100 & $100 \%$ \\
\hline
\end{tabular}

Sources: Field survey.

From the table out of 100 respondents, 83yes that CSR may be practice enough under regulation of the central bank and only 17 respondents supported null hypothesis (H0).

So $\mathrm{H} 0=\mathrm{CSR}$ may not be practice enough under regulation of the central bank.

$\mathrm{H} 1=\mathrm{CSR}$ may be practice enough under regulation of the central bank.

The calculated value of $Z$ is $1-.075$ land table value is |1.96|. (By using the formula of- Z).
Here, calculated value of $\mathrm{Z}$ is lower than table value.

So, it can accept the null hypotheses and reject the alternative hypothesis, CSR may not be practice enough under regulation of the central bank.

\subsubsection{Findings of the Study}

The study reveals the importance of corporate social responsibility as a tool to gain competitive advantage, has positive impact on employees' behavior, customers' behavior and in establishing a bank's image. These all may create reputation and long term interest by all the parties related to the bank. On the basis of the perception of the bank employees, the study identified the level of importance of some core areas of CSR performance.

Among the selected core seven sectors, the respondents have given more importance on the area 'Education'. Finally, the study attempted to find out the selected ten private commercial bank's performances of CSR in some selected important areas.

In this case Dutch Bangla Bank (DBBL) is one of the top most position and The FSIBL, Trust bank and EXIM bank have also a good contribution to CSR and deal with different areas of CSR. Therefore the most of the private commercial banks fall under the average rate. They consider only a few areas. The banks should diversify their CSR practices and considered the other important areas of the society, such as women empowerment, Sanitation in rural areas, rural development activities related to the poverty alleviation. This can ensure the overall development of the country.

For this reason, the central bank, Bangladesh Bank monitoring the CSR adoption and performance of banks and also give some directions to the banks and provide some priority areas for CSR practice. According to Bangladesh Bank's instruction PCB's are working for CSR which are mentioned in annual reports. As a result now a day's CSR practice has an upward trend which is less than compared to any other first world countries.

\section{Opportunities and Challenges of CSR of Banking Sector in Bangladesh}

\subsection{Opportunities of CSR of Banking Sector in Bangladesh}

Corporate social responsibility (CSR) is now growingly viewed as a strategic tool for achieving and maintaining sustainable competitive advantage in the rapidly changing marketplace. Some of the opportunities that can arise when financial institutions and other business organizations adopt a policy of corporate social responsibility (CSR) in Bangladesh include:

- Increase corporate reputation and goodwill: When a company adopts a CSR policy and contributes towards the society, environment and other stake holders, a positive evaluation of the company generally occurs in the marketplace. It can increase the social acceptability of the company as good corporate citizen and enhance its reputation and goodwill. 
- Enhancing firms and brand image: Company or brand image is important because it ultimately provides the company a competitive advantage for their business. By increasing the reputation and goodwill, CSR can be used to enhance the image of the company or to prevent it from potential deterioration.

- Brand differentiation: In crowded marketplaces companies strive for 'X Factors' which can separate them from the competition in the minds of consumers. In Bangladesh, CSR practice can help a bank or NBFI to easily differentiate it from its rival. Organization like Dutch-Bangla Bank Ltd. is well known for their CSR contribution in education and health sector all over the country which enables them occupy separate place in the consumer mind.

- Avoid governmental threat: Any business cannot operate in any country without following the laws and regulations of that particular country. By taking substantive voluntary steps they can persuade governments and the wider public that they are taking current issues like health and safety, diversity or the environment seriously and so avoid intervention.

- Social \& community development: CSR practice makes good business sense of give back to society. Charitable contributions, employee volunteer programs, corporate involvement in community education, employment and homelessness programs, product safety and quality etc. all are directed towards the development of society and community as a whole.

- Environmental protection: CSR practice is synonymous to ensuring sustainable development in countries like Bangladesh. Many companies in Bangladesh are undertaking tree plantation, beach cleaning, greener waste management, greater material recyclability, better product durability and functionality, greater use of renewable resources, integration of environmental management tools into business plans, including lifecycle assessment and costing, environmental management standards, and eco-labeling etc. initiatives to protect environment ant to be recognized as environment friendly.

- Efficient human resources management: Corporate Social Responsibility can be an important aid to recruitment and retention, particularly within the competitive graduate market. CSR can also help to build a 'feel good' atmosphere among existing staff. CSR increase benefits and motivation to staff, increase employee satisfaction, loyalty and retention.

- Increasedcustomer loyalty: When customers see that the company not only earning profit from them, but also supplies them quality products, undertakes social and environmental development programs such as health support, educational scholarship, arts and music preservation and promotion programs and so on, it usually increase the loyalty of customers towards that company.

- Positive word of mouth communication: Increased customer loyalty resulting from visible CSR activities reduces the rate of customer defection and increase positive word of mouth communication.

- Increased sales: In a recent survey it is found that, more than one in five consumers reported having either rewarded or punished companies based on their perceived social performance. Consumers of Bangladesh are growingly conscious about social responsibility of business and tend to reward the company with larger CSR involvement.

- Increase profits: CSR has positive effect on increasing profits. CSR not only increases sales and market share but also lowers the operating costs of the company by increasing workforce productivity and efficiency, protects resources on which the company depends, improves supply chain performance, create positive relationships with other institutional players etc. and thus increase profits of the company.

- Meet the competition: When consumers are in a situation to have a choice between two products or services that are relatively the same, the CSR practice associated with those companies can be an influencing factor in their decision to purchase a product or service.

\subsection{Challenges of CSR of Banking Sector in Bangladesh}

This paper also suggests the following main challenges for implementing CSR in Bangladesh-

- Crisis of conceptualization: There is no universal definition of CSR. Although the essence remains welfare of people and communities, CSR may be masked through vested interests. As it has different meaning, it creates the problems of conceptualization.

- Lack of public awareness regarding CSR: Far reaching education and awareness programmes are required to create a common understanding of CSR across sectors and geographies. Without awareness customers are unable to reward CSR involvement of the company

- Lack of community participation in CSR activities: There is a lack of interest of the local community in participating and contributing to CSR activities of companies. This is largely attributable to the fact that there exists little or no knowledge about CSR within the local communities as no serious efforts have been made to spread awareness about CSR and instill confidence in the local communities about such initiatives..

- Problems of selecting partners: It is also reported that there is non-availability of well-organized nongovernmental organizations in remote and rural areas that can assess and identify real needs of the community and work along with companies to ensure successful implementation of CSR activities.

- Problems of building local capacities: Challenges arise from the need for capacity building of the local nongovernmental organizations as there is serious dearth of trained and efficient organizations that can effectively contribute to the ongoing CSR activities initiated by companies. 
- Lack of trust on CSR: CSR practice always suffers from the problems of distrust. Consumers often view the CSR activities of various companies as a means of emotionally charging to earn more and more profits. General public may also perceive CSR activities as temporary, not sustainable.

- Lack of Transparency: Lack of transparency is one of the key challenges brought forth by the survey. This reported lack of transparency negatively impacts the process of trust building between companies and local communities, which is a key to the success of any CSR initiative at the local level.

- Challenges of invisibility: Like the iceberg, most CSR activity is invisible: The role of media in highlighting good cases of successful CSR initiatives is welcomed as it spreads good stories and sensitizes the local population about various ongoing CSR initiatives of companies.

- Political pitfalls: While CSR is growingly viewed as a strategic tool for achieving sustainable competitive advantage, but political belief of the government or changes in the political party can hinders the CSR programs initiated by specific firms. For example, in Bangladesh several donations of Islami Bank Bangladesh Ltd. to government funds are rejected due to varying political belief of the ruling party.

- Non-availability of clear CSR guidelines and agenda: In Bangladesh, till today, there is no clear cut sector wise or sector specific statutory guidelines or policy directives to give a definitive direction to CSR initiatives of companies.

\section{Limitations, Recommendations and Conclusion}

\subsection{Limitations of the Study}

Although the present study has supplied useful information about CSR practices in Bangladesh, but it is not free from limitations. This study has several limitations that must be acknowledged. The study has the following limitations-

i. The main limitation of this report is that it is based on primary data and secondary data. Although the study suffers from the lack of corresponding primary data.

ii. Another limitation of this report is that the officials of different companies did not disclose specific CSR related data and information for the reason of confidentiality.

iii. The study also relied on various CSR publications, journals, annual reports and relevant web sites. But these analyses did not provide country specific updated CSR information.

iv. As an MBA student, I have to carry on this research project along with my regular curricular activities. So this study suffers from time limitation.

v. I have faced some problems while conducting the research on questionnaire data collection due to lack of practical experiences in the relevant field of research.

\subsection{Recommendations}

If CSR is to be the fruit of a strategic and sustainable corporate commitment and not a temporary fashion fad, its contribution to social and economic progress should be promoted, despite its limitations and weaknesses. In this respect, I have following suggestions:

- Create public awareness regarding CSR among the mass people, academics, managers, and other stakeholders so that they view CSR objectively and get benefit from it when the corporations practice it. CSR education can be spread at all level of our educational system.

- Increase the community participation in CSR activities by promoting a CSR friendly social dialogue. Companies should not only focus on consumers but active dialogue with other stakeholders is crucial for the success of CSR.

- Well organized clear cut guidelines including the sector wise CSR rules, regulations, and policies should be developed as soon as possible.

- Skill development initiatives should be developed for both the internal and external parties. Skills and tools are important to allow stakeholders to play their role properly. For this, organizations can create appropriate institutional frameworks which permit stakeholders to meet and discuss CSR matters.

- Smaller and some medium scale companies have little knowledge of what CSR is. They often do not possess the human and financial resources required for their CSR practices. But fostering CSR among SMEs is crucial for the overall success of CSR practice in countries like Bangladesh as SMEs are the heart of our economy.

- Ensure transparency and build trust on the CSR activities of the companies. Companies should make the stakeholders believe that they are really caring for them, for society, and for broader environment as a whole.

\subsection{Conclusion}

CSR is neither an objective nor an option but an environment offering challenges and opportunities that can also be shaped. Because CSR is based on philanthropy or voluntary activities in Bangladesh, it is of critical importance that CSR must not be a means for business to redefine or reinterpret its existing responsibilities.

It is believed that the interest in CSR initiatives in Bangladesh has been initiated largely by MNCs although the banking sector is one of the key contributors nowadays. As Bangladesh is now come under the global standards, it is anticipated that there will be tremendous growth of CSR initiatives by many national and multinational companies in future. From a marketing point of view CSR is also becoming attractive to Bangladeshi companies for strategic reasons. Companies use their CSR initiatives and past 
records to create the image of socially and environmentally responsible firms and thereby influence consumer buying decisions in favor of the goods and services marketed by them (Quazi et. al.).

As the opportunities and challenges of CSR practice are also apparent for other national level and multi-national companies besides financial sectors, further research can be carried out to cover those areas. Despite considerable progress in this area, the parties involved tend to be of the opinion that an effort is still needed to increase knowledge about the positive impact of CSR on business, people and societies, not only of its underlying conditions but also its limitations. So, I can conclude by saying that, if the challenges of CSR practices can be overcome or minimized, there will be ample growth of CSR practices in our country in future.

\section{References}

[1] Abedin Ahmed, Md. Kayssar. (2013). Corporate Social Responsibility Practices of Commercial Banks in Bangladesh: A Case Study on Southeast Bank Ltd. Journal of Business and Management, Volume 12, Issue 1, 13-18.

[2] Alam, S. M. S. Hoque, S. M. S. and Hosen, M. Z. (2010). Corporate Social Responsibility of Multinational Corporation in Bangladesh: A case study on Grammen Phone. Journal of Pathuakhali Science and Technology University, Vol. 02 No. 01, 51-61.

[3] Arafin, Shaikh. Shamsul, and Hossain. Shamim. (2013). An Overview of Corporate Social Responsibility Activities in Bangladesh: A Study on Commercial Banks. Journal of Business Studies, Vol. 6, 81-96.
[4] Friedman, Milton. (1970). The Social Responsibility of Business is to Increase its Profits. The New York Times Magazine.

[5] Belal, Ataur. R. (2001). A study of corporate social disclosures in Bangladesh. Managerial Auditing Journal, 16 (5), 274-289.

[6] Rangan, Kash, Chase, Lisa. A. and Karim. Sohel. (2012). Why Every Company Needs a CSR Strategy and How to Build It. Harvard Business School. Working Paper 12-88.

[7] Md. Masud Rana, Abul Kalam and Md. Halimuzzaman (2012).Corporate Social Responsibility (CSR) Of DutchBangla Bank Limited: A Case Study. Bangladesh Research Publications Journal, Volume: 7, Issue: 3, 241-247.

[8] Mehta, Tushna. and Majumdar, Aloka. (2012). HSBC: CSR for Corporate Sustainability. Vikalpa, Vol. 37, No. 2, 90-93.

[9] Nimalathasan, B. (2009). Social Responsibility of Business: A Case Study of Grameen Phone in Bangladesh". Annals of University of Bucharest. Economic and Administrative Series, Vol. 3, 227-236.

[10] Rahman, Atiur. (2013). Evolution of CSR in Bangladesh and Future Challenges. CSR Review, Vol. 10, 1-4.

[11] Review of CSR Activities of Financial Sector- 2012 (August, 2013). Published by Bangladesh Bank.

[12] Review of CSR Initiatives in Banks (2008 \& 2009) (April, 2010). Published by Bangladesh Bank.

[13] Review of CSR Initiatives of Banks- 2011 (July, 2012). Published by Bangladesh Bank.

[14] New Hampshire Businesses for Social Responsibility. Corporate Social Responsibility Issues. Retrieved on 05.01.2014. 